\title{
Protagonismo juvenil: análise do projeto Rede de Adolescentes e Jovens Promotores da Saúde (RAP da Saúde) do município do Rio de Janeiro, na perspectiva de seus participantes
}

\section{Youth protagonism: an analysis of the project Network of Adolescents and Young Health Promoters (Rap da Saúde) the city of Rio de Janeiro, from the perspective of its participants}

\author{
Bianca Gonçalves Tasca ${ }^{a}$ \\ (D) https://orcid.org/0000-0002-0737-8052 \\ E-mail: biatasca®gmail.com

\section{Elaine Reis Brandão ${ }^{a}$} \\ (iD) http://orcid.org/0000-0002-3682-6985 \\ E-mail: brandao®iesc.ufrj.br \\ Viviane Manso Castello Branco ${ }^{\text {b }}$ \\ (i) https://orcid.org/0000-0001-8423-8793 \\ E-mail: vivianecbrancoळhotmail.com \\ aUniversidade Federal do Rio de Janeiro. Instituto de Estudos \\ em Saúde Coletiva. Rio de Janeiro, RJ, Brasil. \\ ${ }^{\text {b} F u n d a c ̧ a ̃ o ~ T e ́ c n i c o-E d u c a c i o n a l ~ S o u z a ~ M a r q u e s . ~ E s c o l a ~ d e ~}$ \\ Medicina. Rio de Janeiro, RJ, Brasil.
}

\section{Correspondência}

Bianca Gonçalves Tasca

Universidade Federal do Rio de Janeiro, Cidade Universitária.

Av. Horácio Macedo, s/n. Rio de Janeiro, RJ, Brasil. CEP 21941-598.

\section{Resumo}

O artigo aborda o projeto Rede de Adolescentes e Jovens Promotores de Saúde (Rap da Saúde), da Secretaria Municipal de Saúde do Rio de Janeiro, enquanto estratégia de fomento do protagonismo juvenil, na perspectiva de seus participantes. Para tal, realizou-se uma pesquisa documental nos arquivos do projeto, incluindo 150 trabalhos de conclusão de curso dos jovens participantes da turma de 2018, nos quais avaliam tal experiência de formação. A perspectiva analítica adotada buscou valorizar os relatos juvenis sobre o aprendizado pessoal e profissional conquistados no Rap da Saúde, as dificuldades enfrentadas e o quanto tal vivência em grupo e no contato com profissionais de saúde e diversas instituições sociais os permitiu se tornar jovens mais autoconfiantes, inseridos em suas comunidades e atentos às necessidades de seus pares. Em suma, o trabalho reflete sobre o processo de amadurecimento pessoal e como cidadão de jovens que tiveram a oportunidade de ser protagonistas de atividades educativas e de promoção da saúde em suas respectivas comunidades no município do Rio de Janeiro, no período de setembro de 2017 a setembro de 2018. Palavras-chave: Juventude; Saúde Coletiva; Educação em Saúde; Promoção da Saúde; Capacitação Profissional. 
This article addresses the project Network of Adolescents and Young Health Promoters (Rap da Saúde) from Rio de Janeiro's Municipal Health Secretariat, as a strategy to promote youth protagonism. A documentary research was carried out in the project archives, including 150 graduation papers of the young participants of the 2018 class, in which they evaluated the experience. The analytical perspective adopted sought to value the youth reports on personal and professional learning achieved at Rap da Saúde, the challenges faced by them and how much such experience and the contact with health professionals and various social institutions allowed them to become more self-sufficient, confident, inserted in their communities, and attentive to the needs of their peers. This paper reflects the process of personal development experienced by the participants who had the opportunity to be protagonists of health promotion activities in their communities in the city of Rio de Janeiro from September 2017 to September 2018.

Keywords: Youth; Public Health; Health Education; Health Promotion; Professional Training.
A Rede de Adolescentes e Jovens Promotores da Saúde (RAP da Saúde) é uma iniciativa da Secretaria Municipal de Saúde do Rio de Janeiro (SMS-RJ) de incentivo ao protagonismo juvenil e à educação entre pares na atenção primária à saúde carioca. 0 projeto, iniciado em 2007 , fez parte de uma série de estratégias da SMS-RJ voltadas à saúde dos jovens. Tal empreitada remonta ao fim da década de 1980, momento em que se reconhece a necessidade de mudanças estruturais nos serviços de saúde para possibilitar espaços de discussão juvenis.

As políticas públicas destinadas a jovens e adolescentes permitem compreender as representações sociais atribuídas a estes grupos ao longo do tempo. Na tentativa de delimitar as diferenças entre adolescente e jovem, percebe-se que o primeiro grupo tende a receber um enfoque nos processos biológicos de transformação do corpo e estruturação da personalidade, estando mais presente em estudos do campo da saúde. Já a juventude apresenta-se com mais frequência como objeto da sociologia, onde é analisada em meio ao conjunto das relações sociais (Silva; Lopes, 2009).

0 recorte da juventude é bastante recente nos marcos legais brasileiros, as primeiras menções a estes indivíduos enquanto "sujeitos de direitos" datam da segunda metade da década de 1980. Inicialmente, as políticas públicas eram voltadas aos adolescentes e pretendiam dar conta da dimensão da violência, tida então como sua marca típica, pela suposta propensão a cometer atos criminosos. O Código de Menores de 1979 é um exemplo: este instrumento se direcionava apenas às crianças e adolescentes em situação irregular, termo designado àqueles que estavam sob tutela do Estado (Silva; Lopes, 2009).

No fim da década de 1980, impulsionado por movimentos sociais que participavam da redemocratização brasileira, do movimento de reforma sanitária e de criação do Sistema Único de Saúde (SUS), surge o Programa de Saúde do Adolescente (Prosad). Desenvolvido pelo Ministério da Saúde em 1989 e posteriormente adotado pela SMS-RJ, o Prosad foi o primeiro programa a incentivar a participação social dos jovens na elaboração de políticas públicas na área da saúde (Jager et al., 2014). 
A partir da década de 1990, as políticas públicas passam a enfatizar a participação social dos jovens, tomando-os como sujeitos autônomos (Novaes, 2007). O Estatuto da Criança e do Adolescente (ECA) é um importante marco político-institucional do período. Neste documento reitera-se que crianças e adolescentes são portadores de direitos e não somente objetos de intervenção do Estado ou da família (Brasil, 2010).

O jovem participativo ou ator estratégico do desenvolvimento social também passa a figurar com frequência nas políticas públicas (Silva; Lopes, 2009). No ano de 2005 cria-se, através da Secretaria Nacional da Juventude, o Conselho Nacional da Juventude e a Política Nacional da Juventude (PNJ) - responsáveis por promover a formulação de políticas públicas criadas a partir de demandas das juventudes.

Em 2010, o Ministério da Saúde lança as Diretrizes Nacionais de Atenção Integral à Saúde de Adolescentes na Promoção, Proteção e Recuperação da Saúde com base na Política Nacional de Atenção Integral à Saúde de Adolescentes e Jovens. A participação juvenil é apresentada neste documento como um dos temas estruturantes para a atenção integral à saúde de adolescentes e jovens (Brasil, 2010).

Segundo Regina Novaes (2007), existem três modelos de jovem - o violento, o do grupo de risco e o participativo - que coexistem até hoje no imaginário da população. Ferreira (2017) aponta para novos atributos dos jovens, como a digitalização massiva da experiência e a provisoriedade dos projetos, para exemplificar a dificuldade e constante necessidade de atualização na investigação destes indivíduos enquanto categoria social.

Ao longo do tempo diversos marcadores, como padrões comportamentais e marcas biológicas, foram privilegiados na tentativa de categorizar jovens e adolescentes. Organismos nacionais e internacionais delimitam estes grupos por meio de intervalos etários. Apesar de não ser possível compreendê-los apenas através desta demarcação, tal definição tem permitido a criação de políticas públicas específicas (Minayo; Boghossian, 2009).

O Ministério da Saúde e a Organização Mundial da Saúde estabelecem o período entre 10 e 19 anos, 11 meses e 29 dias como adolescência, e as idades entre 15 e 24 anos como juventude (Brasil, 2010). Já o ECA e o Fundo das Nações Unidas estabelecem que a adolescência vai dos 12 aos 18 anos de idade; e o Estatuto da Juventude, de 2013, determina que a categoria juventude diz respeito a pessoas entre 15 e 29 anos de idade (Brasil, 2013).

No presente artigo considera-se que as categorias adolescências e juventudes são constructos sociais localizados histórica, econômica, social e politicamente (Andrade; Bógus, 2010). Além disso, toma-se a juventude ou adolescência como processo social de passagem para a vida adulta, com marcos característicos do ciclo de vida contemporâneo. Galland (1997) elege o término dos estudos, a primeira experiência profissional, a saída da casa dos pais e o início da vida conjugal como experiências características da trajetória biográfica juvenil da atualidade.

Importante notar que este processo não é homogêneo, em especial na sociedade brasileira, marcada pela desigualdade de direitos e oportunidades. Assim, o perfil dos jovens e adolescentes é múltiplo e suas características dependem de uma intersecção de fatores responsáveis por suas condições de existência, como organização familiar, nível de escolaridade, local de moradia, gênero, raça/cor, dentre outros (Taquette, 2010).

$\mathrm{Na}$ tentativa de retratar os jovens e adolescentes que fizeram parte do RAP da Saúde, temos a cidade do Rio de Janeiro, em que $15,4 \%$ da população é composta por jovens entre 15 e 29 anos. Dentre estes, $24,2 \%$ vivem em domicílios pobres e 10,6\% em extremamente pobres (IPP, 2016). No ano de 2017, a taxa de homicídios por 100 mil jovens na faixa etária de 15-29 anos de idade no estado do Rio de Janeiro foi de 92,6. Estratificando estes dados pelos homens jovens, tem-se a assustadora taxa de 176,2 homicídios por 100 mil (IPEA, 2019). Além do cenário das violências urbanas, soma-se a dificuldade de inserção no mercado de trabalho, o aumento dos casos de suicídio e de infecção pelo vírus da imunodeficiência humana, que atualmente possui a maior taxa de detecção entre jovens dessa faixa etária (Brasil, 2018).

Percebe-se que a realidade das juventudes, principalmente negra e pobre, escancara a desigualdade social do município. Para além das vulnerabilidades da juventude, existe uma potente 
cena cultural e de resistência liderada por jovens no Rio de Janeiro. O passinho, os slams de poesia, bailes funk, coletivos de enfrentamento ao racismo e homofobia são apenas alguns exemplos.

É dentro deste cenário que o RAP da Saúde realizava suas atividades, através de um curso teórico-prático para indivíduos entre 14 e 24 anos de idade. Os jovens selecionados desempenhavam ações de promoção da saúde no intuito de dialogar com seus pares e aproximar a assistência à saúde à realidade jovem carioca. 0 projeto foi descontinuado em 2019 em meio a um cenário de crescente desinvestimento na atenção primária carioca.

O objetivo deste artigo é analisar, através dos relatos de experiência dos jovens da turma de 2018, a avaliação do projeto sob a ótica de seus participantes. Para tal, é feita uma discussão sobre os distintos modos de compreensão do protagonismo juvenil na literatura e da experiência de formação e atuação dos jovens participantes do RAP da Saúde.

Segundo Ferreira (2017), as vozes juvenis raramente são incorporadas aos discursos produzidos sobre adolescentes e jovens. Desta forma, espera-se que os extratos das narrativas dos participantes contribuam para percepção das singularidades das experiências e permitam uma apreensão de suas impressões de forma privilegiada.

A temática surgiu como objeto de pesquisa do artigo após estágio da primeira autora no segundo ano da Residência Multiprofissional em Saúde Coletiva, vinculada ao Instituto de Estudos em Saúde Coletiva da Universidade Federal do Rio de Janeiro (IESC/UFRJ), na Superintendência de Promoção da Saúde da Secretaria Municipal de Saúde do Rio de Janeiro (SPS/SMS-RJ), junto à equipe do RAP da Saúde, de março de 2018 a fevereiro de 2019.

\section{Protagonismo juvenil: da prática política à metodologia de ensino}

Segundo Souza (2006), o termo jovem está intrinsicamente conectado à atuação política dos indivíduos. Enquanto na década de 196o este grupo era representado majoritariamente por universitários de classe média de movimentos estudantis, hoje a categoria abarca um contingente mais extenso de faixas etárias, classes sociais e territorialidades. No entanto, o engajamento político, ou falta dele, segue sendo relacionado à juventude.

Já a proposta do protagonismo juvenil surge no discurso de organismos internacionais em meados da década de 1980. Genericamente, o termo foi tido como incentivo à participação democrática dos jovens na sociedade. Porém, enquanto algumas vezes é usado como conceito teórico, em outras aparece como estratégia política e ainda outras como ferramenta metodológica. Minayo e Boghossian (2009) apontam para a abrangência de significados e alertam para a banalização da expressão entre organizações internacionais, universidades e entidades da sociedade civil, as quais estimulam a participação dos jovens sem de fato especificar do que se trata.

Os primeiros documentos internacionais sobre participação juvenil são da Organização das Nações Unidas, de 1985 - Ano Internacional da Juventude. A partir daí órgãos internacionais passam a incentivar o discurso da participação mais ativa dos jovens na sociedade (Stamato, 2008). Para Minayo e Boghossian (2009) a juventude foi tida como bode expiatório da baixa participação politica dos cidadãos e foi dada a eles a incumbência de alterar este cenário através de sua atuação.

Por meio de uma revisão sistemática, Minayo e Boghossian (2009) identificam alguns fatores que contribuíram para a emergência da discussão sobre protagonismo juvenil: o peso numérico da juventude na população mundial, especialmente da juventude empobrecida que gera preocupação nos organismos internacionais; o contexto de precarização das relações de trabalho; e a elaboração e implementação das políticas públicas da juventude.

Um dos responsáveis pela disseminação da prática do protagonismo juvenil entre entidades do terceiro setor e projetos de promoção da saúde na década de 1990 no Brasil é Gomes da Costa (1999). Segundo ele, o objetivo do protagonismo é formar jovens autônomos, solidários, competentes e participativos.

$\mathrm{O}$ autor, que concebe protagonismo juvenil como ação educativa, explica que nesta metodologia político-pedagógica, o educador deve sair de cena para permitir que o jovem seja o ator principal no seu processo de desenvolvimento. Ao se envolver com tomadas de decisões reais no seu dia a dia, o 
jovem adquire e amplia o seu repertório interativo, podendo assim interferir na realidade ao seu redor (Gomes da Costa, 1999).

Machado Pais (2005), sociólogo português e pesquisador do tema da juventude, por sua vez, aborda o protagonismo juvenil através de uma discussão sobre cidadania - o que é? Para quem? Feita por quem? O protagonismo, a seu ver, é prática inerente de se ser jovem, não uma metodologia pedagógica.

Ainda segundo Pais (2005, p. 65), a ideia de participação juvenil enquanto metodologia possui caráter instrumental que não se propõe a criticar as estruturas da sociedade, não questiona a desigualdade de oportunidades ou o sistema educacional. Neste contexto, a participação juvenil se fundamenta em "educação para o trabalho; trabalho para a consecução de uma cidadania normalizada; cidadania como categoria estável de direitos e obrigações”.

Jáno seu sentido mais político, a ideia de participação diz respeito ao processo de desenvolver consciência crítica e adquirir poder. Para Diaz Bordenave (1994), a participação real visa a transformação das estruturas sociais e econômicas mais amplas. Segundo o autor, a participação que visa apenas o melhoramento de questões pontuais possui função adaptadora.

Regina Souza (2009), por sua vez, afirma que o termo protagonismo juvenil surge como discurso integrador que prescreve ou impõe um modelo determinado de participação, colocando nos indivíduos a responsabilidade por seus êxitos ou fracassos. Ainda segundo a autora, as organizações que utilizam do protagonismo juvenil impedem a fala autônoma e transgressora dos jovens e, na realidade, praticam uma encenação política, atuação social, em defesa de interesses privados.

Assim, percebe-se que o termo protagonismo juvenil é polissêmico e seu uso depende do desejo político de mudança. Ciente das armadilhas do tema, busca-se compreender a percepção dos jovens participantes do RAP da Saúde sobre sua experiência com esta metodologia educativa, ação política ou atuação social no dia a dia de um projeto de promoção da saúde.

\section{Procedimentos metodológicos}

Trata-se de pesquisa documental, baseada no acervo institucional do projeto RAP da Saúde, na
SPS/SMS-RJ. Segundo Lüdke e André (1986), uma das justificativas para a realização de uma pesquisa documental é quando a própria expressão dos indivíduos, a linguagem dos sujeitos, se faz crucial para a investigação.

Os documentos considerados para análise foram os relatos de experiência de 150 jovens participantes do projeto. Os textos foram solicitados pela coordenação do curso como forma de observar a vivência de cada participante no momento de conclusão do ciclo de formação relativo aos anos de 2017-2018. Pediu-se que os relatos abordassem temas como: as expectativas ao entrar no RAP; a relação com companheiros, com os profissionais apoiadores e com a unidade de saúde; as percepções sobre as atividades que desenvolveram; e os locais que transitaram.

Alguns jovens estavam completando o segundo ano do curso $(n=42)$, enquanto outros encerravam o primeiro ano no projeto $(n=108)$. Privilegiou-se estes documentos por acreditar que são ricas fontes de informação que explicitam qualitativamente as impressões dos indivíduos.

A consulta aos arquivos institucionais do RAP da Saúde foi autorizada pela então Superintendente de Promoção da Saúde, mediante solicitação e apresentação da proposta de pesquisa como finalização do estágio prático na Superintendência de Promoção da Saúde da Residência Multiprofissional em Saúde Coletiva (IESC/UFRJ). Tais documentos foram gentilmente disponibilizados pela equipe técnica do projeto para análise e sistematização. A identificação dos jovens autores será mantida em sigilo para respeitar o anonimato e confidencialidade dos relatos.

\section{Rede de Adolescentes e Jovens Promotores de Saúde (RAP da Saúde)}

As iniciativas da SMS-RJ voltadas ao público adolescente se iniciaram, de forma mais sistematizada, em 1992, com a criação da Gerência do Programa de Saúde do Adolescente que seguia as diretrizes do Prosad do Ministério da Saúde. As ações objetivavam promover a saúde integral dos adolescentes, através de intervenções transdisciplinares e intersetoriais que possibilitassem o seu desenvolvimento e autonomia (Branco, 2002). 
O investimento em ações de protagonismo juvenil iniciou em 1993 e culminou com a criação do Adolescentro Maré, no ano 200o, e do Adolescentro Paulo Freire, em 2004. "Essas experiências revelaram a potencialidade dos jovens para a promoção da saúde e a qualificação da atenção primária e abriram caminho para a criação do RAP da Saúde em 2007" (Rio de Janeiro, 2014, p. 2).

O RAP da Saúde, inicialmente denominado Rede de Adolescentes Promotores da Saúde, foi implantado com o objetivo de ampliar ações de promoção da saúde por meio de estratégias de protagonismo juvenil e educação entre pares (Branco et al., 2015). O projeto foi estabelecido pela Assessoria de Promoção da Saúde da SMS-RJ, por meio de convênio com a organização não governamental Centro de Promoção da Saúde (Cedaps). Inicialmente o público prioritário do projeto era composto apenas por adolescentes, mas em 2012 os jovens passaram a integrar o grupo. "O projeto valoriza o dinamismo dos jovens e investe na sua capacidade de desenvolver atividades criativas que ampliem o diálogo entre os serviços de saúde, as escolas, as comunidades e as políticas públicas" (Rio de Janeiro, 2014, p. 4). Nesse sentido, a formação, tanto dos jovens quanto dos profissionais, e o planejamento conjunto com as equipes, são elementos fundamentais do projeto.

De 2007 a 2009, no primeiro ciclo do RAP da Saúde, havia equipes de adolescentes em três unidades de saúde, atuando em cinco comunidades: Complexo da Maré, Rocinha, Vidigal, Vila Canoas e Complexo do Alemão. Este ciclo buscou disseminar, para unidades de saúde com diferentes níveis de complexidade, as experiências bem sucedidas de promoção da saúde, prevenção de agravos e ação intersetorial voltadas à adolescentes, já desenvolvidas nos adolescentros.

De 2010 a 2012, no segundo ciclo do RAP, o projeto passou a ser gerenciado pela Coordenação de Políticas e Ações Intersetoriais da Superintendência de Promoção da Saúde. Nesse período o RAP se integrou à Plataforma de Centros Urbanos (PCU), do Fundo das Nações Unidas para a Infância (Unicef), iniciativa voltada à promoção de direitos de crianças e adolescentes na busca pela diminuição das desigualdades intramunicipais que afetam capitais brasileiras. Esta fase enfatizou a capilarização das ações de promoção da saúde nas comunidades em situação de vulnerabilidade social. Em 2011, o RAP recebeu o prêmio Pró-Equidade em Saúde (Conasems, Fiocruz e Ministério da Saúde) (Rio de Janeiro, 2014).

De 2012 a 2014, em seu terceiro ciclo, o projeto se reorganizou em equipes territoriais em oito das dez áreas de planejamento da cidade. Este momento priorizou a institucionalização na rede de atenção primária, disseminação da metodologia para outras unidades de saúde, qualificação da articulação intersetorial e fortalecimento de outros grupos jovens. Nesse período o RAP se consolidou como uma tecnologia social para a qualificação da promoção da saúde e da atenção primária no SUS, tendo sido uma das iniciativas premiadas pelo Laboratório de Inovações em Saúde do Adolescente (Rio de Janeiro, 2014).

Em 2015 o RAP entrou em seu quarto momento, passou a ser gerido exclusivamente pela SMS-RJ e adquiriu formato de curso de formação para jovens promotores de saúde (Rio de Janeiro, 2017). Os jovens eram selecionados para integrar o projeto através de processo seletivo direcionado a moradores das 10 áreas programáticas do município do Rio de Janeiro. A divulgação do edital era realizada através do diário oficial da SMS-RJ e de mídias sociais como Facebook e WhatsApp. Em 2017 a coordenação do projeto recebeu mais de 10 mil inscrições para preencher 242 vagas.

O curso visava:

formar jovens para atuar como promotores de saúde no âmbito da rede de atenção primária, fortalecendo o protagonismo juvenil, prática educativa em que o jovem é elemento central e participa de todas as fases do processo educativo, desde a elaboração, execução e avaliação das ações propostas, com o objetivo de estimular a participação social do jovem na comunidade. (Rio de Janeiro, 2017, p. 3)

Os jovens selecionados eram divididos entre multiplicadores, dinamizadores e facilitadores. Os Multiplicadores eram jovens sem qualquer tipo de experiência em promoção da saúde e possuíam uma carga horária de 12 horas semanais com bolsa de R\$30o,oo e auxílio transporte mensal. Os Dinamizadores, por sua vez, tinham maiores responsabilidades no planejamento e desenvolvimento 
das atividades junto aos profissionais apoiadores das unidades de saúde. Eles possuíam carga horária de 16 horas semanais com bolsa de R\$40o,oo e auxílio transporte. Já os chamados jovens Facilitadores estavam no projeto há mais de um ano e auxiliavam os polos na articulação de parcerias nos territórios, na integração entre os polos, as Coordenadorias de Atenção Primária (CAP) e o Nível Central. Recebiam bolsa de R\$6oo,oo mensais e tinham carga horária de 16 horas semanais. Na turma de 2018 analisada neste artigo, havia 16 jovens Facilitadores, 40 Dinamizadores e 184 Multiplicadores.

A estrutura do RAP da Saúde contava com três tipos de profissionais apoiadores: os do chamado Nível Central da SMS-RJ, alocados na Superintendência de Promoção da Saúde, responsáveis pela coordenação das atividades das dez áreas programáticas; profissionais apoiadores das 10 CAP, responsáveis pela articulação das atividades do projeto nas unidades de saúde de seu território; e os profissionais apoiadores das Unidades de Saúde - Clínicas da Família e Centros Municipais de Saúde - que acompanhavam a rotina do projeto.

Os apoiadores das unidades de saúde eram profissionais que já desempenhavam uma função e passaram a acumular a tarefa de apoiador do RAP. Esperava-se que eles possibilitassem um espaço para diálogo e troca, fornecendo elementos para a auxiliar os jovens na elaboração de atividades, no aprofundamento de temáticas e articulação com outros dispositivos dos territórios.

Uma vez selecionados, os jovens eram alocados em unidades de saúde próximas a sua residência. Em 2018 havia, em média, cinco jovens por unidade e em torno de 40 unidades com jovens do RAP da Saúde. A carga horária dedicada ao projeto dividia-se em exposições teóricas, ministradas por profissionais de saúde da rede da SMS-RJ e parceiros institucionais, discussão entre os jovens, escolha das temáticas a serem trabalhadas e criação de atividades de promoção da saúde no território.

Nas unidades de saúde, os jovens eram estimulados a usar a criatividade para desenvolver atividades que abordassem temáticas correlatas à promoção da saúde. Alguns conteúdos acompanhavam o calendário da saúde, como Dia Mundial sem Tabaco, Setembro Amarelo e Mês de Conscientização das
Hepatites Virais, outros surgiam por iniciativa dos jovens conforme seus interesses e de suas unidades e comunidades.

As atividades de formação ofereciam a jovens e profissionais conteúdo teórico, reflexão sobre valores e atitudes, além da vivência de diferentes dinâmicas. No entanto, no nível local, as equipes de jovens e profissionais tinham autonomia e, tanto as atividades realizadas quanto a sua metodologia ficavam a critério dos polos de atuação, segundo necessidades identificadas. Dentre as mais realizadas estavam: atividades de promoção da saúde na sala de espera; rodas de conversa; elaboração e apresentação de esquetes teatrais, apresentações de dança, paródias, criação de conteúdo audiovisual, entre outras.

Os locais de realização destas atividades também variavam de acordo com a demanda do território e avaliação dos jovens: escolas, Centros de Referência de Assistência Social (Cras), praças da região, metrô e shoppings estavam entre alguns dos lugares de preferência dos jovens.

Dentre os 242 jovens que passaram pelo RAP da Saúde nos anos de 2017 e 2018, 142 (59\%) eram do sexo feminino e 100 ( $41 \%$ ) do sexo masculino. A distribuição segundo identidade de gênero autodeclarada foi $57 \%$ feminina ( $n=140$ ), $41 \%$ masculina $(n=100)$ e o,8\% transgênero $(n=2)$. A média de idade dos jovens foi de 18 anos.

Quanto à distribuição por cor e raça, a maioria se classificou como parda (43\%), seguida por preta (33\%) e branca (20\%). Com relação à escolaridade, $81 \%$ dos jovens estavam estudando no momento que ingressaram no projeto, $47 \%$ no ensino médio e $32 \%$ no ensino fundamental em escolas públicas.

\section{A voz dos jovens participantes}

Voltando o olhar para as narrativas dos jovens sobre a participação no RAP da Saúde, temos nos seus relatos bons indicadores dos significados de tal vivência para eles. Muitos jovens introduzem suas narrativas contando que se inscreveram no projeto desejando se instrumentalizar e se capacitar para o mercado de trabalho, e viram no RAP a oportunidade de se aproximarem da área da saúde.

Alguns participantes já conheciam a unidade para a qual foram designados por realizarem tratamento 
de saúde no local e passaram a descobrir um "outro lado" do estabelecimento; puderam se aproximar dos funcionários e transitar por novos locais na unidade, não apenas como usuários.

A presença do profissional de saúde apoiador se mostrou de suma importância. Segundo os relatos juvenis, a forma com que foram recebidos pelos apoiadores nas unidades fez diferença para que se sentissem à vontade e tivessem compromisso e responsabilidade com as atividades. Alguns profissionais apoiadores realizaram encontros de integração com os jovens, o que foi importante para criação de uma coesão grupal.

Eu nunca fui uma menina com a autoestima alta, então foi difícil me sentir útil. Minha apoiadora desde o início apostou na conversa em grupo. No decorrer das conversas, começamos a nos dar conta que a nossa fala era bastante peculiar. Estava um tanto evidente que poderíamos explorá-la na prática e ver no que poderia dar. (C.0, 17 anos, mulher)

No entanto tal experiência não era regra, por vezes os profissionais apoiadores não se indentificavam com o projeto ou a recepção nas unidade não se dava de forma harmoniosa, impondo algumas barreiras na adaptação dos jovens.

Uma coisa que foi muito difícil foi o preconceito que as pessoas e até mesmo alguns funcionários da clínica tinham conosco, em achar que só pelo fato de sermos jovens, não poderíamos trabalhar ou exercer uma função na clínica. Nos julgavam dizendo que jovem só faz bagunça e desacreditavam nossa capacidade de promover a saúde. (D.F, 16 anos, mulher)

No início o formato do projeto gerou surpresa, alguns jovens acreditavam que a formação teria moldes mais tradicionais, dentro de sala de aula com professores e avaliações. O fato do RAP se designar "curso" e acontecer dentro das unidades de saúde também gerava confusão. Foi preciso um tempo de adaptação para que os participantes compreendessem que o projeto apostava na iniciativa dos próprios jovens e deixava em seu cargo a elaboração das atividades educativas e de promoção da saúde.
Além disso, ficou evidente no material analisado que participar do curso dentro de uma unidade de saúde, perto ou no território em que vivem, os permitiu enxergar o local de moradia de outra forma, percebendo os determinantes sociais de saúde da região.

Acima de tudo, me orgulho de ter passado na vida de tanta gente dentro do meu território, falando de coisas que eram tão distantes pra mim e perceber que realmente impactava a vida delas. O RAP me fez entender a importância do SUS, passei a ver a saúde pública com outros olhos. Entendi como funcionam as clínicas e os profissionais. Tem muito o que melhorar ainda, mas quando entendemos a sua importância, passamos a valorizar mais. (T.A, 18 anos, mulher)

Percebe-se que os jovens apreciaram muito os momentos de capacitação, tanto com os profissionais das unidades de saúde quanto os das CAP e do nível central da SMS-RJ. Com relação às temáticas trabalhadas, expressam preferência por aquelas que abordam a realidade em que vivem e o momento de vida pelo qual estão passando. A temática dos direitos sexuais e reprodutivos é uma das mais citadas.

Uma atividade que me marcou foi a esquete de gravidez na adolescência por eu estar grávida e estar passando por algumas coisas citadas na esquete. Eu estou em uma etapa muito bonita da minha vida, porém complicada. No inicio do RAP eu engravidei. Demorei para saber da existência do meu bebê e quando soube fiquei com medo de contar; achei que iriam me julgar e criticar como as pessoas ao meu redor estavam fazendo. Foi tudo ao contrário, me ajudaram a ver que nem tudo é ruime que nada está perdido. me ajudaram a gostar mais da minha gravidez. (N.H, 16 anos, mulher)

Os temas relacionados aos direitos humanos, racismo e participação política também geraram muito interesse. Alguns jovens disseram ter tido o primeiro contato com tais conteúdos através do RAP e perceberam que pouco se discute a respeito nos locais em que transitam. Importante destacar também as oficinas de psicodrama, muito felicitadas por proporcionarem momentos de autoconhecimento e integração entre os jovens. 
Com o transcorrer do ano, os jovens foram compreendendo que cabia a eles planejar e realizar as ações, de modo que foram encontrando voz dentro do grupo e aprendendo a trabalhar e conviver com seus companheiros. A partir do momento em que passaram a estudar e se instrumentalizar, os participantes relataram maior desenvoltura para transmitir informações. Alguns se tornaram referências "da saúde" em seus territórios e apreciaram tal reconhecimento.

Posso falar que mudei também a forma de me comunicar na escola ou até mesmo com pessoas que acabei de conhecer, dando mais valor para as pessoas que tiram uma parte do seu tempo para falar sobre assuntos importantes. Posso falar que agora conheço os dois lados e sei como é levar informação onde não se tem. (P.P, 17 anos, mulher)

Os vínculos afetivos criados através do projeto são muito mencionados. Os jovens com frequência falam da "nova família" da qual fazem parte com os amigos, apoiadores e demais profissionais das unidades de saúde. Vale pontuar também que muitos integrantes do RAP descreveram que a relação com seus familiares melhorou ao longo do ano. Passaram a dialogar mais com seus pais, irmãos e avós, dividindo suas preocupações e questionamentos.

Tive a oportunidade de conviver com realidades diferentes da minha, que acredito que engrandecem muito na minha formação de ser humano, pois quanto maior o contato com diversidades, maior se torna a capacidade de compreender e respeitar outros indivíduos. Seja no território quando estou em atividade ou na minha vida social fora do $R A P$, por exemplo, quando chego em casa e posso conversar com maior propriedade e desmistificar alguns tabus que as pessoas têm sobre a saúde pública. (D.P, 20 anos, mulher)

A partir da possibilidade de vivenciar situações novas os jovens passaram a se envolver mais em debates políticos, a descontruir relações de poder e a perceber a importância de expor suas ideias. Além disso, alguns jovens contam ter adquirido novo entendimento do que é saúde e de seus direitos enquanto cidadãos e usuários do SUS.

Quando entrei no RAP era católica, e tinha o pensamento pequeno para certas coisas. Comecei a ter bastante contato com a diversidade, percebi que cada um tem um jeito, uma forma de pensar, uma criação diferente e opiniões diferentes. Hoje eu defendo com unhas e dentes o movimento LGBT e faço isso porque entendi que a vida do outro é do outro e não tenho o direito de mandar e desmandarquemvocêvai amare se isso é errado ou não. (M.N, 17 anos, mulher)

Visto que o RAP da Saúde realizava atividades em diversos locais, a possibilidade de conhecer lugares e transitar pela cidade também foi destacada nas narrativas. Os jovens puderam se apropriar de espaços, a exemplo de visitas a museus, debates em universidades, oficinas no Departamento Geral de Ações Socioeducativas (Degase) com jovens internos e, inclusive, participação em eventos no Ministério da Saúde em Brasília.

\section{Considerações finais}

No esforço de concluir, é importante frisar que o RAP da Saúde é um projeto desenvolvido em uma instituição pública de saúde norteada pelos princípios da integralidade, universalidade e equidade (Brasil, 2010). Trata-se de uma iniciativa que buscou incorporar a participação social de adolescentes e jovens na execução de políticas de saúde a este segmento.

O projeto passou por diferentes fases desde sua criação e conta com uma grande rede de atores, termo tomado aqui como sujeitos que interpretam e exercitam o protagonismo juvenil de diversas formas. Além disso, o projeto demandava a capacitação dos profissionais das unidades de saúde para que pudessem apoiar os jovens participantes, estabelecendo uma relação mais horizontal entre eles. A equipe muitas vezes não estava acostumada a lidar com este público e o fato dos jovens transitarem pelas unidades permitia que os profissionais aprendessem, na lida diária, a melhor forma de se relacionarem com estes usuários. 
Fomentar o protagonismo juvenil nos serviços de saúde é um grande desafio. Há uma tensão permanente entre as demandas da unidade e da SMS-RJ e os desejos dos jovens. Diversas ações eram propostas, planejadas e desenvolvidas pelos jovens a partir das necessidades que eles próprios identificavam. No entanto, esta autonomia de criação e o apoio para sua realização dependiam também da identificação, generosidade e capacidade de negociação por parte dos profissionais de saúde.

As informações e metodologias utilizadas no projeto forneciam um arcabouço teórico e prático para atuação nas unidades de saúde e também nos demais locais em que os jovens transitavam, escola, círculo familiar, local de moradia, entre outros. Assim, estes conseguiam advogar pelo direito do sigilo no atendimento a adolescentes e a orientar amigos sobre onde buscar a assistência de saúde necessária, por exemplo. Com isso, percebe-se que o projeto auxiliava na garantia do acesso à saúde dos jovens em seus territórios.

Não é possível avaliar os impactos do projeto na trajetória dos participantes, uma vez que muitos fatores determinam o percurso de vida de uma pessoa. No entanto, os jovens foram incentivados a explorar seus interesses e refletir sobre determinantes sociais da saúde e seus reflexos na saúde da população. Com isso, o projeto os auxiliou a adquirir consciência crítica. São jovens que passaram a integrar comitês de discussão sobre saúde da população negra, que puderam custear cursos de línguas com a bolsa e outros que engravidaram e decidiram ter seus filhos sabendo das dificuldades que enfrentariam com essa escolha.

Além disso, o projeto considerava a saúde em diferentes dimensões, focando em um trabalho intersetorial. Os jovens tiveram a oportunidade de discutir, dentro de seus territórios, temas como desejo, política, ecologia, sexualidade e projeto de vida. Com isso, defende-se aqui que o projeto permitiu a efetivação de direitos, gerando oportunidades para que os jovens construíssem suas próprias trajetórias de autonomia e emancipação. Esse resultado é fruto da crença na potência dos jovens e do fortalecimento da parceria entre eles e os profissionais de saúde.

\section{Referências}

ANDRADE, E. A.; BÓGUS, C. M. Políticas públicas dirigidas à juventude e promoção da saúde: como a proposta de auxiliares da juventude foi traduzida em prática. Interface, Botucatu, v. 14, n. 35, p. 853-866, 2010.

BRANCO, V. M. C. Emoção e razão: os sentidos atribuídos por profissionais de saúde à atenção ao adolescente. 2002. Dissertação (Mestrado em Saúde Coletiva) -Universidade Federal do Rio de Janeiro, Rio de Janeiro, 2002.

BRANCO, V. M. C. et al. Caminhos para a institucionalização do protagonismo juvenil na SMS-Rio: dos adolescentros ao RAP da Saúde. Adolescência e Saúde, Rio de Janeiro, v. 12, p. 14-22, 2015. Suplemento 1.

BRASIL. Ministério da Saúde. Secretaria de Atenção em Saúde. Departamento de Ações Programáticas Estratégicas. Diretrizes nacionais para a atenção integral à saúde de adolescentes e jovens na promoção, proteção e recuperação da saúde. Brasília, DF, 2010.

BRASIL. Lei $\mathrm{n}^{0}$ 12.852, de 5 de agosto de 2013. Institui o Estatuto da Juventude e dispõe sobre os direitos dos jovens, os princípios e diretrizes das políticas públicas de juventude e o Sistema Nacional de Juventude - SINAJUVE. Diário Oficial da União, Brasília, DF, 6 ago. 2013.

BRASIL. Ministério da Saúde. Secretaria de Vigilância em Saúde. Departamento de Vigilância, Prevenção e Controle das IST, HIV/Aids e Hepatites Virais. HIV Aids, 2018. Brasília, DF, 2018. Boletim Epidemiológico.

DIAZ BORDENAVE, J. E. O que é participação. São Paulo: Brasiliense, 1994.

FERREIRA, V. S. (Org.). Pesquisar jovens: caminhos e desafios metodológicos. Lisboa: Imprensa de Ciências Sociais, 2017.

GALLAND, O. Sociologie de la jeunesse. Paris: Armand Colin, 1997. 
GOMES COSTA, A. C. O adolescente como protagonista. Cadernos Juventude, Saúde e Desenvolvimento, Brasília, DF, v. 1, p. 75-79, 1999.

IPEA - INSTITUTO DE PESQUISA ECONÔMICA APLICADA. Atlas da violência 2019. Brasília, DF, 2019. Disponível em: <https://bit.ly/304GybE>.

Acesso em: 22 jan. 2020.

IPP - Instituto Pereira Passos. Agentes da

Transformação. Rio de Janeiro, 2016. Caderno da Juventude Carioca. Disponível em:

<https://bit.ly/2X3YJfQ>. Acesso em: 20 jan. 2020.

JAGER, M. E. et al. O adolescente no contexto da saúde pública brasileira: reflexões sobre o PROSAD. Psicologia em Estudo, Maringá, V. 19, n. 2, p. 211-221, 2014.

LÜDKE, M.; ANDRÉ, M. E. D. A. Pesquisa em educação: abordagens qualitativas. São Paulo: EPU, 1986.

MINAYO, M. C.; BOGHOSSIAN, C. O. Revisão sistemática sobre juventude e participação nos últimos 10 anos. Saúde e Sociedade, São Paulo, v. 18, n. 3, p. 411-423, 2009.

NOVAES, R. C. R. Juventude e sociedade: jogos de espelhos, sentimentos, percepções e demandas por direitos e políticas públicas. Sociologia Especial: ciência e vida, São Paulo, v. 1, n. 2, p. 6-15, 2007.

PAIS, J. M. Jovens e cidadania. Sociologia, Problemas e Práticas, Lisboa, n. 49, p. 53-70, 2005. RIO DE JANEIRO. Secretaria Municipal de Saúde. RAP da Saúde: Rede de Adolescentes e Jovens Promotores da Saúde. Boletim Circulador. Rio de Janeiro, 2014.

RIO DE JANEIRO. Secretaria Municipal de Saúde. Edital Conjunto S/SUBG/CGGP e S/SUBPAV/SPS $\mathrm{n}^{0} 1$, de 7 de julho de 2017. Diário Oficial, Rio de Janeiro, 8 jul. 2017. Disponível em:

<https://bit.ly/3oTxTbc>. Acesso em: 18 abr. 2020.

SILVA, C. R.; LOPES, R. E. Adolescência e juventude: entre conceitos e políticas públicas. Cadernos de Terapia Ocupacional da UFSCar, São Carlos, v. 17, n. 2, p. 87-106, 2009.
SOUZA, R. M. O discurso do protagonismo juvenil. 2006. Tese (Doutorado em Sociologia) - Faculdade de Filosofia, Letras e Ciências Humanas, Universidade de São Paulo, São Paulo, 2006.

SOUZA, R. M. Protagonismo juvenil: o discurso da juventude sem voz. Revista Brasileira

Adolescência e Conflitualidade, [S.l.], v. 1, p. 1-28, 2009.

STAMATO, M. I. C. Protagonismo juvenil: uma práxis sócio histórica de ressignificação da juventude. 2008. Tese (Doutorado em Psicologia Social) - Pontifícia Universidade Católica de São Paulo, São Paulo, 2008.

TAQUETTE, S. R. Interseccionalidade de gênero, classe e raça e vulnerabilidade de adolescentes negras às DST/aids. Saúde e Sociedade, São Paulo, v. 19, p. 51-62, 2010. Suplemento 2.

\section{Contribuição das autoras}

Tasca e Brandão conceberam e desenharam a pesquisa. Tasca coletou e analisou os dados sob supervisão de Brandão. Brandão e Branco interpretaram e executaram a revisão crítica do conteúdo intelectual. Todas as autoras colaboraram com a redação e revisão final do manuscrito.

Recebido: 21/05/2020

Aprovado: 12/07/2020 